\title{
Caracterização climática e estudo de tendências nas séries temporais de temperatura do ar e precipitação em Taubaté (SP) \\ (doi:10.4136/ambi-agua.6)
}

\author{
Marcelo Theophilo Folhes'; Gilberto Fisch ${ }^{2}$ \\ ${ }^{1}$ Instituto Nacional de Pesquisas Espaciais - INPE \\ Caixa Postal 515 - 12201-970 - São José dos Campos-SP, Brasil \\ E-mail:folhes@dsr.inpe.br \\ ${ }^{2}$ Departamento de Ciências Agrárias - Universidade de Taubaté - UNITAU \\ Taubaté-SP, Brasil \\ E-mail: gfisch@uol.com.br
}

\section{RESUMO}

Este trabalho tem por objetivos apresentar as principais características da distribuição temporal da precipitação e da temperatura do ar em Taubaté (SP), além de estabelecer uma caracterização do período da estação chuvosa, bem como verificar a ocorrência de tendências nas séries temporais desses dois elementos climáticos por meio do teste não paramétrico sazonal de Mann-Kendall. Devido à relativa variabilidade interanual da precipitação, não se verificaram tendências significativas no seu valor médio anual. Contudo, as análises da série temporal de 1983 a 2005 mostraram tendência de aumento das chuvas no mês de novembro, redução em abril e uma diminuição do número de dias por ano sem precipitação. Observou-se que o início da estação chuvosa em Taubaté ocorre em meados de setembro e o final acontece em meados de abril.

Palavras-chave: Tendências climáticas; Teste de Mann-Kendall; Estiagem climatológica.

\section{Climate assessment and trend analysis in air temperature and precipitation time series in Taubaté (SP)}

\begin{abstract}
The main objectives of this paper are to present the temporal climatic characteristics of precipitation and air temperature in Taubate (SP), in addition to the characterization of the rainy season. The time trend of the climatic elements were studied using the non parametric seasonal Mann-Kendall test. Statistically, no significant average changes in precipitation were detected although a relatively large natural year-to-year variability there exits. A short-term increasing trend from 1983 to 2005 have been observed in November precipitation, a decreasing trend in the amount of the April precipitation and a decreasing trend in the number of dry days per year. This study suggests that the onset of the Taubaté's rainy season occurs in mid-September and the end is in April.
\end{abstract}

Keywords: Climatic Trend; Mann-Kendall Statistical Test; dry spell. 


\section{INTRODUÇÃO}

A informação climática é importante nas atividades atuais do homem, quer seja para se precaver de fenômenos atmosféricos adversos, quer seja para auxiliar e otimizar a produção agropecuária. A busca pela otimização da prática agrícola é uma questão estrategicamente fundamental diante da necessidade de produzir alimentos para uma população cada vez maior. Nesse sentido, supõe-se que as informações meteorológicas colocadas à disposição dos agricultores são de fundamental importância para o correto planejamento da produção agrícola. Estima-se que apenas esse setor primário da economia, no qual o agronegócio é uma área em franco desenvolvimento, foi responsável por 9,5\% do Produto Interno Bruto (PIB) do Brasil no ano base de 2004 (Brasil, 2005).

Muito se discute, atualmente, sobre a questão de mudanças climáticas, sendo que, para a região do Sudeste Brasileiro, as previsões dos cenários futuros apontam para um aumento da precipitação e da temperatura da ordem de 3 a $4{ }^{\circ} \mathrm{C}$ (Machado; Marengo, 2006). Associado a essas mudanças, também poderá ocorrer um aumento do número de eventos extremos, provocando prejuízos sociais e econômicos. Segundo o relatório Stern (2006), perdas econômicas equivalentes a 3\% das riquezas produzidas por todas as nações são esperadas nas próximas décadas devido aos impactos das mudanças climáticas globais e ao aumento de eventos extremos, tais como tempestades severas, inundações, períodos de estiagens mais prolongados, etc.

Nesse contexto, este trabalho visa apresentar os valores médios e extremos de temperatura do ar e precipitação medidos no posto meteorológico da Universidade de Taubaté (UNITAU), estabelecer uma possível caracterização do início e fim da estação chuvosa nessa região do país, bem como proceder a uma avaliação da série temporal desses elementos climáticos a fim de subsidiar as questões sobre mudanças climáticas na região. Espera-se que os resultados deste trabalho contribuam para o melhor entendimento da climatologia do Vale do Rio Paraíba do Sul.

\section{REVISÃO BIBLIOGRÁFICA}

Nos últimos anos, vários estudos se preocuparam em tentar caracterizar as condições climatológicas da região de Taubaté (Fisch, 1995; Fisch, 1999; Nunes; Calbet, 2000), cujo enfoque maior foi dado ao elemento climático precipitação. Esses estudos descreveram especialmente as características do regime pluviométrico, analisaram detalhadamente sua variabilidade interanual, mas não se preocuparam em investigar a provável ocorrência de tendências na série de dados temporais de precipitação.

Estudos desenvolvidos por Sugahara (1991), Fisch (1995), Sansigolo (1996) e Marengo et al. (2002) procuraram estabelecer uma climatologia de início e fim da estação chuvosa para o estado de São Paulo, Vale do Rio Paraíba do Sul e Região Sudeste do Brasil. Com base nos dados de precipitação acumulada a cada 5 dias (pêntadas), Sugahara (1991), Fisch (1995) e Sansigolo (1996) determinaram que a estação chuvosa tem início no final de setembro e começo de outubro, e que o final ocorre em abril e início de maio. Em média, segundo Marengo et al. (2002), as primeiras chuvas significativas, que prenunciam o início da estação chuvosa na bacia do Rio Paraíba do Sul, ocorrem entre 08 de setembro e 12 de outubro (pêntada 51).

Recentemente, Marengo e Alves (2005) estudaram a ocorrência de tendência hidrológica na Bacia do Rio Paraíba do Sul, usando longas séries temporais de dados de precipitação e vazão fluvial para várias localidades na região e concluíram que, embora tenham observado vazões com tendências negativas, não há como associar tal redução a uma possível 
diminuição da precipitação, mas sim à forma de gerenciamento das águas dos reservatórios da região (principalmente o reservatório de Paraibuna). Nesse mesmo estudo, os autores observaram um aumento da precipitação anual nos postos de Caçapava (série temporal de dados de 1930-2000) e de Cachoeira Paulista (1933-2000), embora a tendência positiva não fosse estatisticamente significante.

Fisch e Valério (2005) investigaram a variabilidade anual da precipitação observada no Vale do Paraíba e sua relação com fenômenos de teleconexão global, como é o caso dos eventos El Nino ou La Nina. Não foi observada uma conexão forte (do tipo causa/efeito) entre os eventos El Nino/La Nina e as chuvas anuais ou mesmo sazonais no Vale do Paraíba.

Em um estudo da variabilidade climática do estado de São Paulo, Dufek e Ambrizzi (2005) utilizaram cinco índices climáticos para investigar a ocorrência de tendências na série de dados temporais de temperatura do ar, tais como "dias quentes", "dias frios", "noites quentes", "noites frias" e "amplitude da temperatura diurna". De forma geral, o estudo aponta uma tendência a condições mais quentes no estado, explicado em parte pelo aumento da temperatura mínima associada à diminuição de noites frias, e pelo aumento da temperatura máxima associada à diminuição de dias frios.

\section{MATERIAL E MÉTODOS}

Os dados dos elementos climáticos utilizados neste trabalho foram coletados no posto meteorológico do Departamento de Ciências Agrárias da Universidade de Taubaté (UNITAU), localizado no município de Taubaté, na região do Vale do Rio Paraíba do Sul. O posto está situado nas coordenadas geográficas $23^{\circ} 02^{\prime} \mathrm{S}$ e $45^{\circ} 30^{\prime} \mathrm{W}$, numa cota 577 metros acima do nível do mar.

Os dados de precipitação estão sendo coletados desde julho de 1982, quando foi instalado o posto meteorológico. Os dados de temperatura do ar à superfície foram coletados a partir de agosto de 1992, quando o posto meteorológico foi ampliado, por meio de uma cooperação técnico-científica com o Instituto Nacional de Meteorologia (INMET), e passou a integrar a rede de observações meteorológicas do Brasil (Sistema Global de Telecomunicações - GTS).

$\mathrm{Na}$ avaliação da precipitação foram considerados os totais mensais, sazonais e anuais e, em relação à temperatura do ar, foram considerados os valores médios mensais de temperaturas máxima e mínima, e seus valores mensais extremos, tais como temperatura máxima absoluta e mínima absoluta. Os valores mensais de precipitação foram calculados como totais mensais (precipitação integrada ao longo de um dia e, posteriormente, ao longo do mês), ao passo que os valores de temperatura média foram calculados pela determinação das temperaturas médias diárias e mensais.

Sobre as variáveis estudadas (temperatura e precipitação) foram aplicados testes estatísticos de análises não paramétricas por meio do teste Sazonal de Mann-Kendall (SMK) para verificar a ocorrência de tendências estatisticamente significativas nas séries de dados temporais.

O teste SMK, proposto inicialmente por Sneyers (1975), é recomendado pela Organização Meteorológica Mundial (OMM) em estudos de tendências em séries temporais de elementos climáticos ( $\mathrm{Yu}$ et al., 2002). Esse mesmo teste também foi utilizado por Machado e Marengo (2006) para estudos hidrológicos no Vale do Rio Paraíba do Sul. O teste considera que, assumindo a hipótese nula $\left(\mathrm{H}_{\mathrm{o}}\right)$ de estabilidade de uma série temporal, os valores da variável aleatória são independentes e igualmente distribuídos. 
Dado uma série temporal aleatória $\mathrm{X}_{1}, \ldots \mathrm{Xi}, \ldots \mathrm{X}_{\mathrm{n}}$ a ser analisada na comprovação de $\mathrm{H}_{0}$, deve-se primeiro calcular a posição ou a ordem de cada elemento $X_{i}$ em relação aos outros valores da série, de forma que $R_{1}, \ldots R_{i}, \ldots R_{n}$ representa a série de números que especificam a ordem relativa de cada elemento da série temporal de $X_{i}$. $O$ passo seguinte consiste em determinar o sinal de cada número-ordem pelas funções sinal $\left(R_{j}-R_{i}\right)$ :

$$
\begin{aligned}
& \operatorname{sinal}\left(R_{j}-R_{i}\right)=1, \operatorname{para} R_{j}-R_{i}>0 \\
& \operatorname{sinal}\left(R_{j}-R_{i}\right)=0, \operatorname{para} R_{j}-R_{i}=0 \\
& \operatorname{sinal}\left(R_{j}-R_{i}\right)=-1, \operatorname{para} R_{j}-R_{i}<0
\end{aligned}
$$

Sob a hipótese nula $\mathrm{H}_{\mathrm{o}}$ de ausência de tendência de variação (quer seja positivo ou negativo), o teste consiste no somatório apresentado na equação abaixo:

$$
S=\sum_{j=i+1}^{n} \operatorname{sinal}\left(R_{j}-R_{i}\right)
$$

Supondo que $\mathrm{H}_{\mathrm{o}}$ seja verdadeira, então a estatística $\mathrm{S}$ apresenta uma distribuição aproximadamente normal gaussiana, com média igual a zero e variância (VAR) conforme a seguinte equação:

$$
\operatorname{VAR}(S)=n(n-1)(2 n+5) / 18
$$

Quando o teste é aplicado para séries temporais mensais de observações, deve ser levado em consideração a covariância entre os valores mensais no cômputo da variância do teste estatístico. Nesse caso os dados são agrupados em uma matriz do tipo:

$$
X=\left[\begin{array}{ccc}
X_{1,1} & \cdots & X_{1,12} \\
\vdots & & \vdots \\
X_{n, 1} & \cdots & X_{n, 12}
\end{array}\right]
$$

$E$ a respectiva matriz de ordem de cada observação em $X$ como sendo:

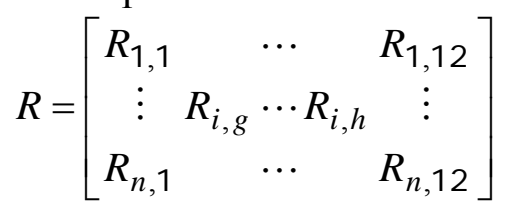

A estatística $S_{\mathrm{g}}$ para cada mês tem a seguinte formulação:

$$
S_{g}=\sum_{j=i+1}^{n} \operatorname{sinal}\left(R_{j, g}-R_{i, g}\right)
$$

em que, $\mathrm{g}=1,2, \ldots, 12$ que representa os meses do ano $($ Janeiro $=1$, Dezembro $=12)$.

Sob $\mathrm{H}_{0}$, o teste estatístico sazonal de Mann-Kendall é dado por:

$S=\sum_{g=1}^{12} S_{g}$

Supondo que $\mathrm{H}_{\mathrm{o}}$ seja verdadeira, então a estatística $\mathrm{S}$ apresenta uma distribuição aproximadamente normal com média igual a zero e variância VAR de acordo com a equação:

$$
\operatorname{VAR}(S)=\sum_{g=1}^{12} \operatorname{VAR}\left(S_{g}\right)+\sum_{\substack{g, h=1 \\ g \neq h}}^{12} \operatorname{COV}\left(S_{g}, S_{h}\right)
$$

A covariância $\operatorname{COV}\left(\mathrm{S}_{\mathrm{g}}, \mathrm{S}_{\mathrm{h}}\right)$ é dada por:

$$
\operatorname{COV}\left(S_{g}, S_{h}\right)=\left[K_{g, h}+4 \sum_{i=1}^{n} R_{i, g} R_{i, h}-n(n+1)^{2}\right] / 3
$$

em que, 


$$
K_{g, h}=\sum_{\mathrm{j}=\mathrm{i}+1}^{\mathrm{n}} \operatorname{sinal}\left[\left(\mathrm{X}_{\mathrm{j}, \mathrm{g}}-\mathrm{X}_{\mathrm{i}, \mathrm{j}}\right)\left(\mathrm{X}_{\mathrm{j}, \mathrm{h}}-\mathrm{X}_{\mathrm{i}, \mathrm{h}}\right)\right]
$$

Finalmente, o valor da estatística MK é dado por:

$$
M K=\left\{\begin{array}{ccc}
\frac{S-1}{\sqrt{\text { VAR(S) }}} & \text { se } & S>0 \\
0 & \text { se } & S=0 \\
\frac{S+1}{\sqrt{\text { VAR(S) }}} & \text { se } & S<0
\end{array}\right.
$$

Com base na análise da estatística MK, é feita a decisão final de aceitar ou rejeitar $\mathrm{H}_{\mathrm{o}}$, ou seja, pode-se confirmar a hipótese de estabilidade dos dados ou rejeitá-la a favor da hipótese alternativa, ou seja, de existência de tendência nos dados. O sinal da estatística MK indica se a tendência é crescente $(M K>0)$ ou decrescente $(M K<0)$.

Num teste bilateral para tendência, $H_{o}$ deve ser aceito se $|\mathrm{MK}| \leq \mathrm{Z}_{\alpha / 2}$, em que o valor de $Z_{\alpha / 2}$ é obtido da Tabela na Normal Reduzida. Em geral, considera-se o nível de significância do teste $\alpha=0,05$, o que corresponde a aceitar a Hipótese $\mathrm{H}_{\mathrm{o}}$ para uma probabilidade de $95 \%$.

\section{RESULTADOS}

\subsection{Precipitação}

A Figura 1 ilustra a distribuição do total anual de chuvas no município de Taubaté, no período de 1983 a 2005. Constata-se que a menor ocorrência de chuvas no município foi observada em 1984, com apenas $854 \mathrm{~mm}$, ao passo que o maior valor $(1687 \mathrm{~mm})$ foi registrado em 1989, ressaltando a alta variabilidade temporal da precipitação na região. A precipitação anual média desse período é de $1350 \mathrm{~mm}$, muito próximo da normal climatológica $(1352 \mathrm{~mm})$ determinada pelo INMET e analisada por Fisch (1995).

Em Taubaté, assim como em toda a região do Vale do Rio Paraíba do Sul, as chuvas mais significativas iniciam-se em setembro de cada ano e estendem-se até o início de abril do ano seguinte (Figura 2). A análise da distribuição da precipitação pelas estações do ano permite concluir que, aproximadamente, $44 \%$ da precipitação anual ocorrem no verão (trimestre dez., jan. e fev.), enquanto o inverno (trimestre jun., jul.e ago.) é a estação menos chuvosa, com cerca de $7 \%$ do total da precipitação anual. As estações de transição, primavera (trimestre set., out. e nov.) e outono (trimestre mar., abr. e mai.) contribuem com os restantes $50 \%$ da precipitação total, repartidos, aproximadamente, de forma eqüitativa.

As séries sazonais de precipitação em Taubaté são apresentadas na Figura 3. A característica mais significativa que se observa nessa figura é a aparente tendência de redução da precipitação no outono ao longo do período analisado, acompanhada de ligeiro aumento de precipitação na primavera, quando comparada com a precipitação sazonal média histórica. No inverno, a variabilidade interanual da precipitação é maior em relação às demais estações do ano, com ocorrência tanto de invernos muito secos quanto de invernos muito chuvosos.

A visualização dos totais e da média das variáveis selecionadas corresponde à análise exploratória do padrão temporal dos dados de precipitação. Segue-se agora o cálculo da estatística Sazonal de Mann-Kendall para verificar se há tendência estatisticamente significativa nas séries temporais de dados de precipitação registrados no posto meteorológico. Os resultados das tendências são apresentados na Tabela 1. 
A observação da Tabela 1 permite concluir que não foram encontradas tendências significativas nas variáveis de precipitação analisadas com o teste SMK, com exceção dos meses de abril e de novembro, para as quais foram encontradas tendências estatisticamente significativas no nível de confiança de 95\% (Figura 4).

As tendências aparentes observadas na precipitação sazonal que ocorrem na primavera e no outono, conforme mencionado anteriormente, devem-se, principalmente, ao significativo aumento e diminuição dos totais de precipitação nos meses de novembro e abril, respectivamente. A forma gráfica do teste SMK é apresentada na Figura 6, em que as linhas horizontais representam os limites críticos dos intervalos de confiança bilaterais de $99 \%$ (linha cheia) e de 95\% (linha pontilhada). A tendência é significativa quando os valores absolutos da estatística MK são maiores do que os limites de confiança, o que acontece exatamente nos meses de abril e novembro.

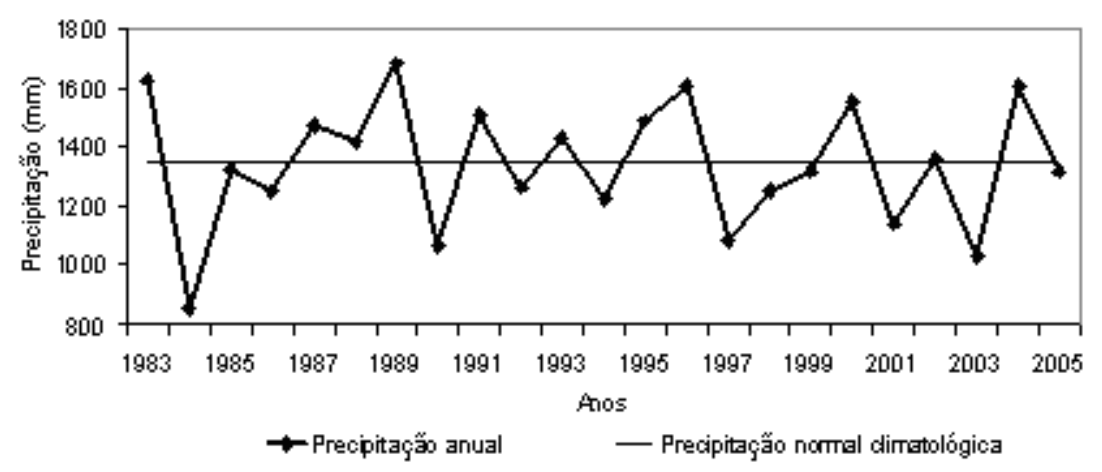

Figura 1. Série temporal da precipitação total anual em Taubaté.

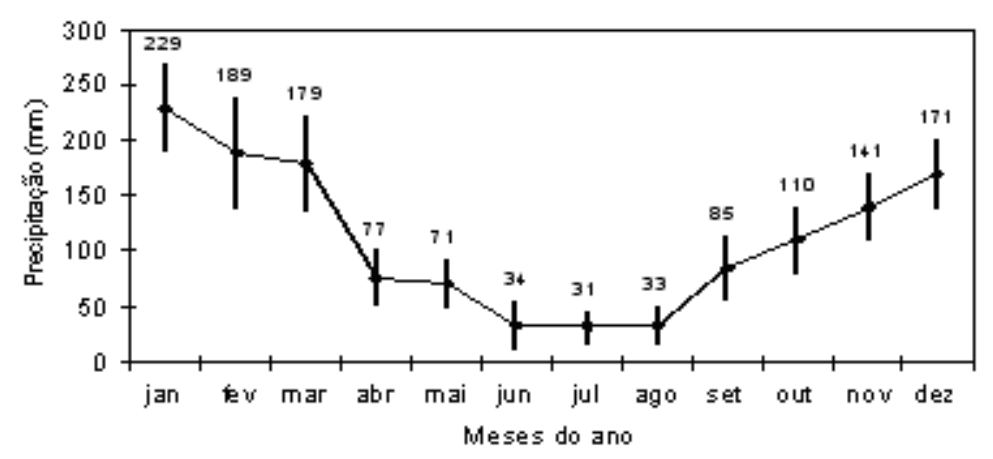

Figura 2. Precipitação média mensal e desvio- padrão em Taubaté.

Apesar da curta série temporal de dados de precipitação, é possível formular algumas hipóteses para as tendências observadas. O aumento significativo das precipitações em novembro (primavera) em grande parte é explicado pelo efeito do aparente aumento de temperatura do ar na região, conforme constatado em Dufek e Ambrizi (2005), que facilita e intensifica o processo de convecção natural e a conseqüente formação de chuvas convectivas. No caso da redução das precipitações em abril (outono), deve-se salientar que a passagem de sistemas frontais na região, nessa época do ano, provoca, com freqüência, a ocorrência de chuvas (Fisch, 1999). Entretanto, com o aquecimento da atmosfera que se observa no nível global, de acordo com Stern (2006), as massas de ar experimentam mais dificuldades em se deslocar pela região Sudeste do Brasil, com a conseqüente redução de chuvas frontais. Os meses de inverno possuem um total de chuva muito pequeno para registrar essas tendências, 

do ar e precipitação em Taubaté (SP). Ambi-Agua, Taubaté, v. 1, n. 1, p. 61-71, 2006. (doi:10.4136/ ambiagua.6)

mas a precipitação do outono apresenta aproximadamente $25 \%$ da precipitação anual (Fisch, 1999) e, com isso, consegue-se observar esse sinal de redução da precipitação.

Tabela 1. Resultados das análises de tendência com nível de confiança de 95\% e 99\%.

\begin{tabular}{l|c|c|c}
\hline \multirow{2}{*}{ Variável analisada } & Teste de Mann-Kendal & \multicolumn{2}{c}{ Tendência } \\
\cline { 3 - 4 } & (Z calculado $)$ & $\alpha=0,05$ & $\alpha=0,01$ \\
\hline Precipitação - anual & $-0,092$ & $\mathrm{NS}$ & $\mathrm{NS}$ \\
Precipitação mensal - abril & $-2,430$ & $-\mathrm{S}$ & $\mathrm{NS}$ \\
Precipitação mensal - novembro & 2,086 & $+\mathrm{S}$ & $\mathrm{NS}$ \\
Estiagem climatológica - anual & $-2,512$ & $-\mathrm{S}$ & $\mathrm{NS}$ \\
Estiagem climatológica - primavera & $-2,733$ & $-\mathrm{S}$ & $-\mathrm{S}$ \\
\hline
\end{tabular}

NS = tendência não significativa; $+S$ = tendência significativa positiva; $-S$ = tendência significativa negativa.

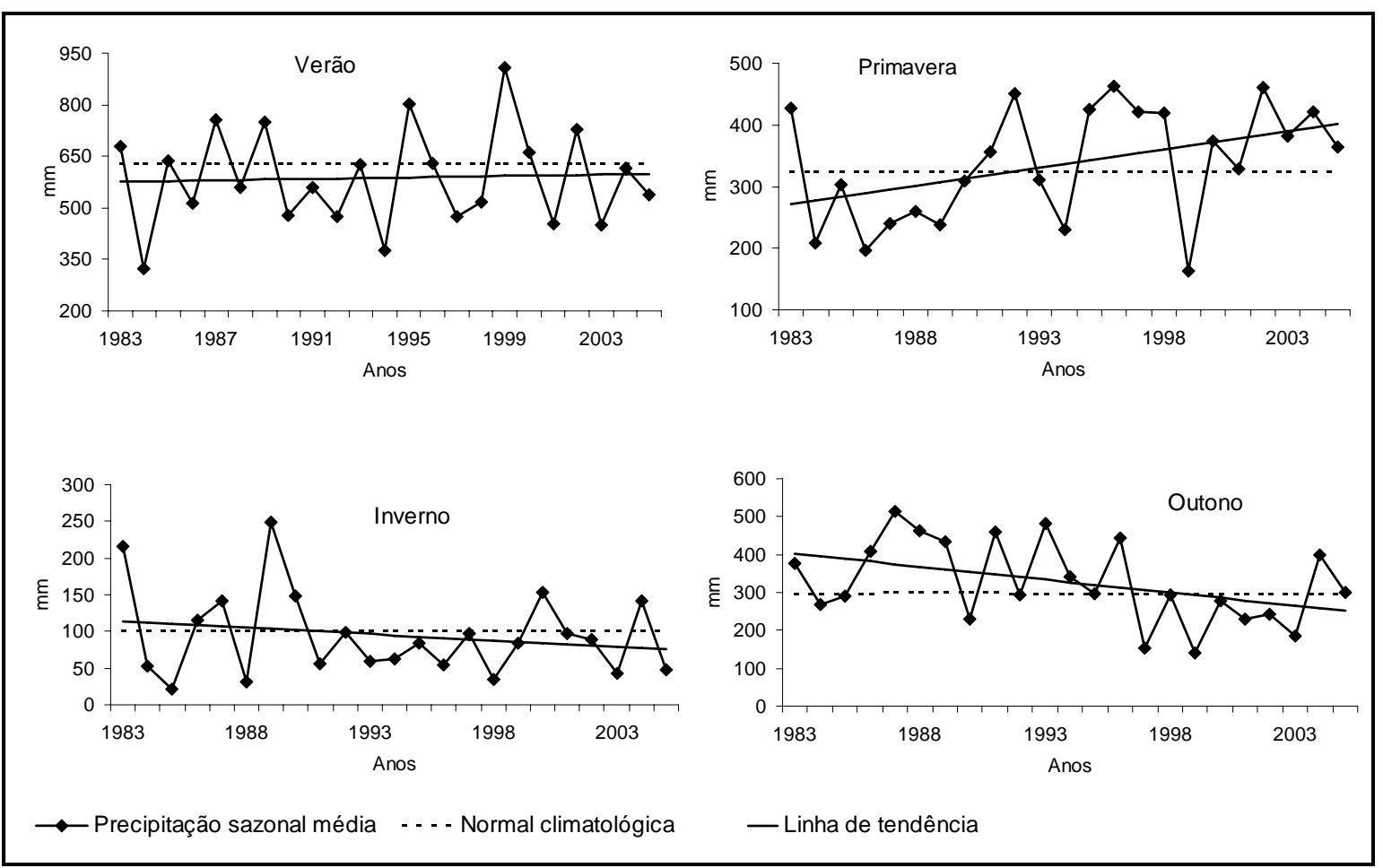

Figura 3. Evolução temporal da precipitação sazonal em Taubaté.

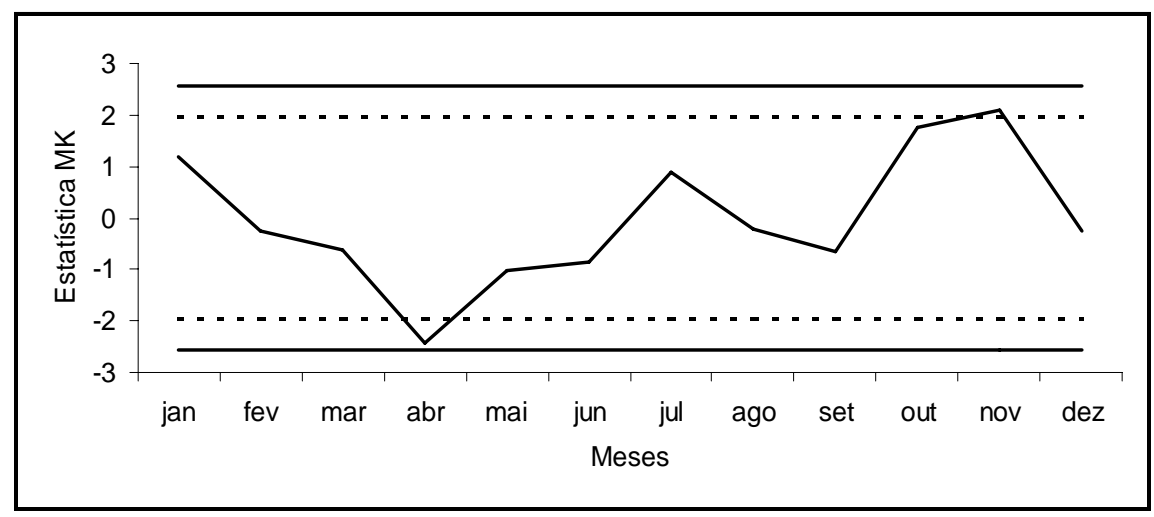

Figura 4. Estatística MK do teste de sazonal de Mann-Kendal referente aos meses do ano. 
Adicionalmente, foi feita uma caracterização sobre as datas esperadas de início e fim da estação chuvosa na região do vale do Paraíba. Este trabalho atualizou a metodologia utilizada por Fisch (1999), que se baseia na chuva acumulada a cada cinco dias (pêntadas). O critério adotado determina para o início da estação chuvosa a primeira pêntada após três pêntadas consecutivas com precipitação acumulada igual ou superior a $45 \mathrm{~mm}$, enquanto o final da estação chuvosa é definido como a pêntada, a partir da qual ocorrem três pêntadas consecutivas com precipitação inferior a $45 \mathrm{~mm}$. Cabe ressaltar que, inicialmente, foram calculados valores médios de precipitação para cada pêntada, usando a série temporal completa (23 anos). Sendo assim, em média, as primeiras chuvas significativas, que indicam para o início da estação chuvosa no vale do Paraíba, ocorrem entre 18 e 22 de setembro (pêntada 53); já o final da estação chuvosa ocorre entre 6 e 10 de abril (pêntada 20) (Figura $5)$.

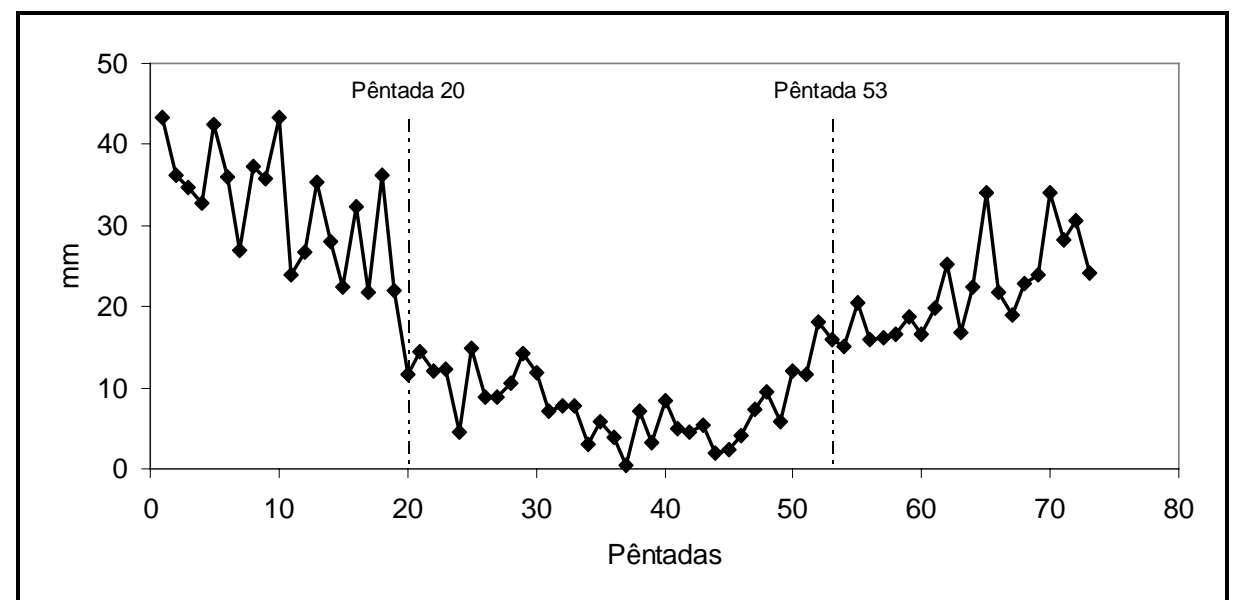

Figura 5. Série temporal de precipitação média acumulada em pêntadas, em Taubaté.

Outro aspecto analisado com relação ao estudo da variabilidade da precipitação é a estiagem climatológica, definida como sendo o número de dias por ano sem precipitação. $\mathrm{Na}$ Figura 6, é possível visualizar uma redução do número de dias sem chuvas na série anual observada, sendo que esse evento é particularmente acentuado na estação da primavera (estatísticas apresentadas na Tabela 1). Esse fato mostra-se coerente com os resultados apresentados na Figura 3, em que se nota um aumento da água precipitada na primavera.

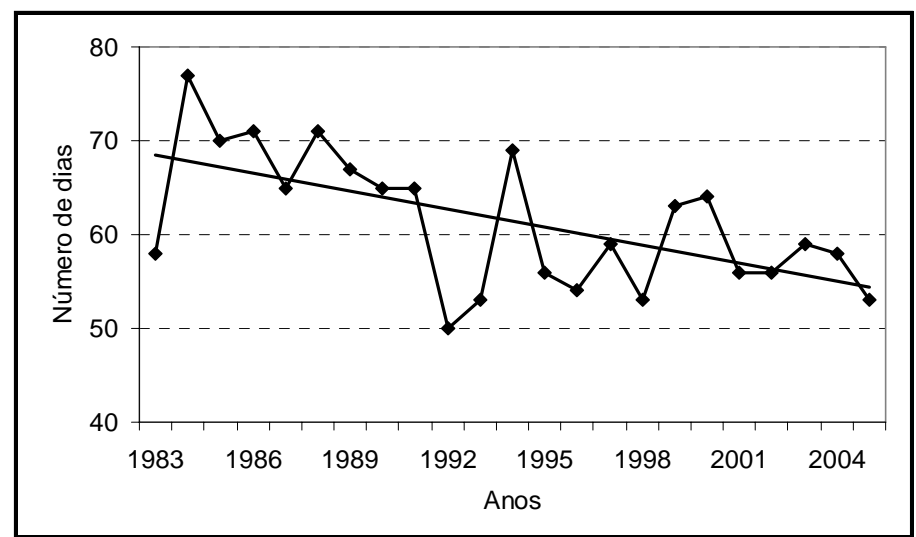

Figura 6. Número anual de dias com estiagem climatológica. 


\subsection{Temperatura do ar à superfície}

A temperatura média anual do ar no período de 1992 a $2005^{1}$ foi de $21,9^{\circ} \mathrm{C}$, muito próxima da normal climatológica $\left(21,7^{\circ} \mathrm{C}\right)$ do INMET (Fisch, 1995), com o valor mínimo de $21,3^{\circ} \mathrm{C}$ registrada em 1996 , e máximo de $22,7^{\circ} \mathrm{C}$ em 2002 . As médias de temperatura nas estações do ano são apresentadas na Tabela 2. Nesse período, a temperatura média à superfície variou entre um mínimo de $12,2^{\circ} \mathrm{C}$ no inverno, e um máximo de $30,6^{\circ} \mathrm{C}$ no verão. Os valores de temperatura absoluta extrema medidos no posto meteorológico foram de $0,9^{\circ} \mathrm{C}$ para a mínima (em julho/1994) e $37,8^{\circ} \mathrm{C}$ para a máxima (em setembro/1997).

Tabela 2. Valores médios de temperatura do ar, máxima e mínima.

\begin{tabular}{cccc}
\hline $\begin{array}{c}\text { Estação } \\
\text { do ano }\end{array}$ & $\begin{array}{c}\text { Temperatura } \\
\text { média do ar } \\
\left({ }^{\circ} \mathrm{C}\right)\end{array}$ & $\begin{array}{c}\text { Temperatura } \\
\text { média mínima } \\
\left({ }^{\circ} \mathrm{C}\right)\end{array}$ & $\begin{array}{c}\text { Temperatura } \\
\text { média máxima } \\
\left({ }^{\circ} \mathrm{C}\right)\end{array}$ \\
\hline Primavera & 23,6 & 17,5 & 29,6 \\
Verão & 24,8 & 19,0 & 30,6 \\
Outono & 19,9 & 13,6 & 26,2 \\
Inverno & 19,1 & 12,2 & 26,0 \\
\hline
\end{tabular}

A série temporal dos valores mensais de temperatura média, máxima e mínima são apresentados na Figura 7. Verifica-se que a menor média do ano ocorre no mês de julho $\left(17,8^{\circ} \mathrm{C}\right)$, enquanto no mês de fevereiro é registrada a maior média $\left(25,1^{\circ} \mathrm{C}\right)$. A média das temperaturas mínimas do ar, no mês de julho pode atingir até $10,9^{\circ} \mathrm{C}$, ao passo que a média das temperaturas máximas chega a valores superiores a $31^{\circ} \mathrm{C}$ em fevereiro. $\mathrm{O}$ mês do ano com maior coeficiente de variação é outubro, caracterizando maior variabilidade na temperatura do ar.

De forma geral, o teste SMK indica que nenhuma tendência significativa na temperatura do ar foi detectada, com exceção da tendência decrescente da temperatura mínima extrema no mês de fevereiro, como pode ser evidenciado na Tabela 2. A forma gráfica do teste Sazonal de Mann-Kendall para a temperatura mínima extrema do ar é apresentada na Figura 8.

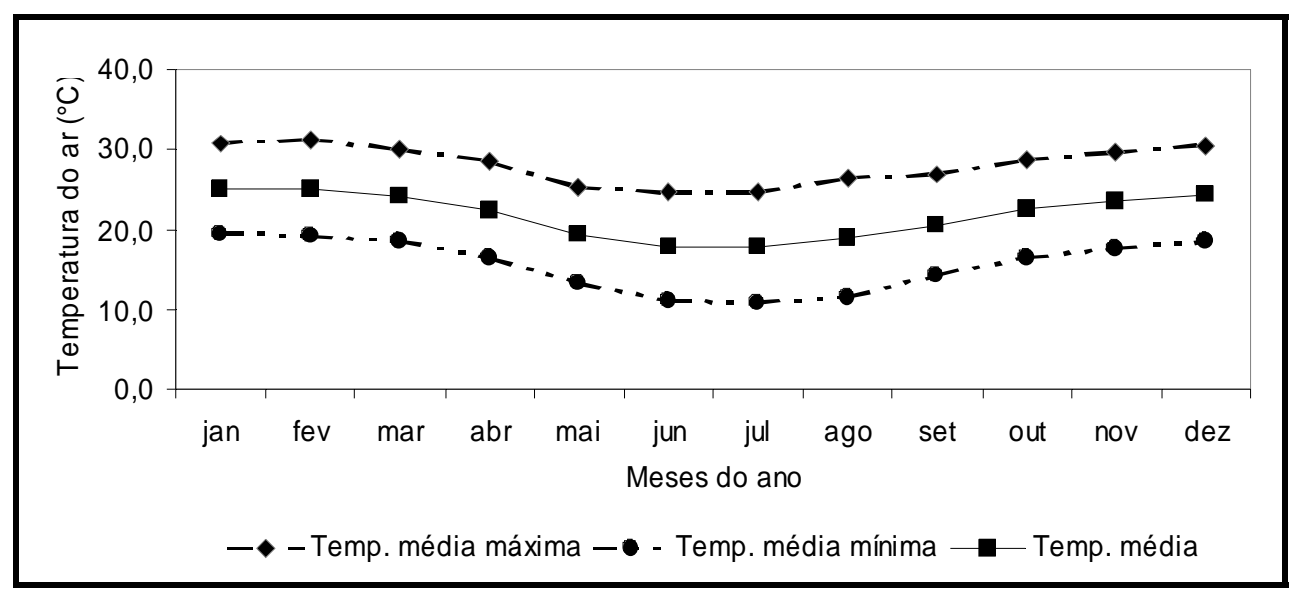

Figura 7. Valores mensais de temperatura média, máxima e mínima.

\footnotetext{
1 Cabe salientar a diferença entre o período de coleta de dados de precipitação e temperatura do ar. As medições de precipitação na UNITAU iniciaram-se em 1982, mas o posto meteorológico (com a instalação do abrigo meteorológico e sensores de Temperaturas do Ar, Máxima e Mínima) somente ocorreu em 1992.
} 
FOLHES, M. T.; FISCH, G. Caracterização climática e estudo de tendências nas séries temporais de temperatura do ar e precipitação em Taubaté (SP). Ambi-Agua, Taubaté, v. 1, n. 1, p. 61-71, 2006. (doi:10.4136/ ambiagua.6)

Tabela 2. Resultados das análises de tendência, nível de significância de 95\% e 99\%.

\begin{tabular}{l|c|c|c}
\hline \multirow{2}{*}{ Variável analisada } & \multirow{2}{*}{$\begin{array}{c}\text { Teste de Mann-Kendal } \\
(\mathbf{Z} \text { calculado) }\end{array}$} & \multicolumn{2}{|c}{ Tendência } \\
\cline { 3 - 4 } & 0,958 & $\mathrm{\alpha}=\mathbf{0 , 0 5}$ & $\boldsymbol{\alpha}=\mathbf{0 , 0 1}$ \\
\hline Temperatura média anual & 0,819 & $\mathrm{NS}$ & $\mathrm{NS}$ \\
Temperatura média máxima anual & 0,264 & $\mathrm{NS}$ & $\mathrm{NS}$ \\
Temperatura média mínima anual & $-2,470$ & $-\mathrm{S}$ & NS \\
Temperatura mínima extrema - fevereiro &
\end{tabular}

$\mathrm{NS}=$ tendência não significativa; $+\mathrm{S}=$ tendência positiva; $-\mathrm{S}=$ tendência negativa.

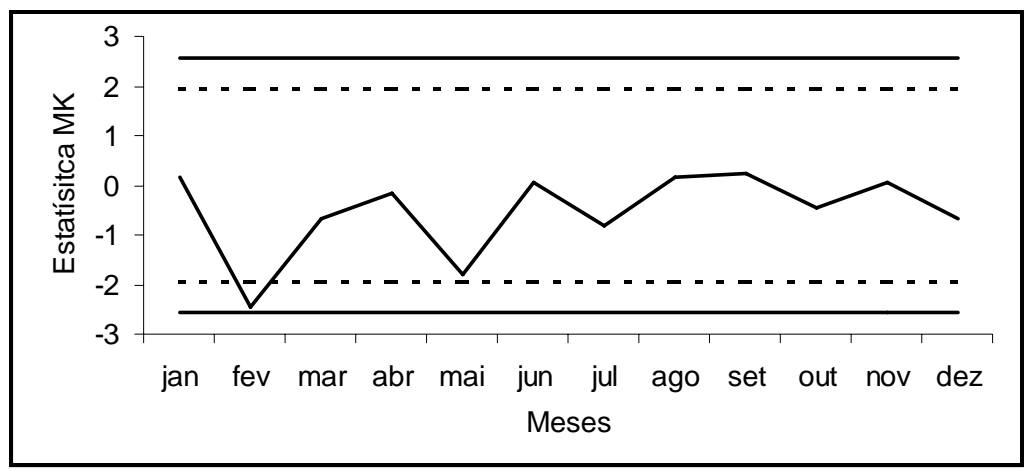

Figura 8. Estatística MK do teste de sazonal de Mann-Kendal.

\section{CONCLUSÕES}

Este estudo procedeu a caracterização e análise da evolução de dois elementos climáticos, temperatura do ar e precipitação, na região de Taubaté. Os resultados apresentados, integrando as informações disponíveis no posto meteorológico da UNITAU, indicam que não há tendência significativa na série temporal de 14 anos de registros de temperatura do ar, com exceção da tendência decrescente da temperatura mínima extrema no mês de fevereiro. No caso da precipitação, no período 1983-2005, as análises mostraram tendência de aumento das chuvas no mês de novembro e também diminuição do número de dias secos. Por outro lado, a precipitação no mês de abril apresenta uma pequena redução estatisticamente significativa. Em termos de precipitação anual, essas duas tendências se equivalem e acabam se anulando, de modo que os testes estatísticos aplicados sobre a série temporal de 23 anos de dados de precipitação anual não apresentaram nenhum indício de tendência positiva ou negativa. Porém, estudos mais detalhados e completos, utilizando uma série temporal maior, necessitam ser realizados para confirmar a hipótese de estabilidade dos dados de temperatura do ar e precipitação no Vale do Rio Paraíba do Sul.

\section{REFERÊNCIAS}

BRASIL. Ministério do Planejamento, Orçamento e Gestão. Instituto Brasileiro de Geografia e Estatística. Participação das atividades econômicas no valor adicionado bruto, por Unidade da Federação - 2001-2004. Rio de Janeiro: IBGE, 2005. Disponível em: $<$ http://www.ibge.gov.br>. Acesso em 08 fev. 2006. 
DUFEK, A. S.; AMBRIZZI, T. Variabilidade climática da chuva e temperatura no Estado de São Paulo. In: SIMPÓSIO DE INICIAÇÃO CIENTÍFICA DO INSTITUTO DE ASTRONOMIA, GEOFÍSICA E CIÊNCIAS ATMOSFÉRICAS, 10., 2005, São Paulo. Resumos... São Paulo: [S.n.], 2005.

FISCH, G. Caracterização climática e balanço hídrico de Taubaté (SP). Revista Biociências, Taubaté, v. 1, n. 1, p. 81- 90, 1995.

FISCH, G. Distribuição da precipitação em Taubaté, Vale do Paraíba (SP). Revista Biociências, Taubaté, v. 5, n. 2, p. 7-11, 1999.

FISCH, G.; VALERIO, M. C. Variabilidade intra e interanual da precipitação em Taubaté-SP associado aos eventos El Nino e La Nina. Revista Biociências, Taubaté, v. 11, n. 1/2, p. 19-29, 2005.

MACHADO, M. A.; MARENGO, J. A. Mudanças climáticas globais e seus efeitos sobre a agricultura brasileira. Newsletter do Projeto GOF-UK-CPTEC, São José dos Campos, v. 1, n. 2, p. 4-6, março 2006.

MARENGO, J. A.; ALVES, L. M. Tendências hidrológicas da Bacia do Rio Paraíba do Sul. Revista Brasileira de Meteorologia, Rio de Janeiro, v. 20, n. 2, p. 215- 226, 2005.

MARENGO, J. A.; ALVES, L. M.; CASTRO, C. A. C; MENDES, D. Início da estação chuvosa nas Regiões Sudeste, Centro-Oeste e sul do Nordeste do Brasil, afetadas pela crise de energia. In: Energia: monitoramento hidrometeorológico: CPTEC/INPE, 2002. Disponível em: <http://www.cptec.inpe.br/energia/saiba/iniciochuvas.shtml $>$. Acesso 02 maio 2006.

NUNES, L. H.; CALBET, N. O. Variabilidade pluviométrica no Vale do Paraíba Paulista. In: CONGRESSO BRASILEIRO DE METEOROLOGIA, 11., 2000, Rio de Janeiro. Anais... Rio de Janeiro: Sociedade Brasileira de Meteorologia, 2000. 1 CD-ROM.

SANSÍGOLO, C. A.; 1996. Variabilidade interanual da estação chuvosa no Estado de São Paulo. Revista Brasileira de Agrometeorologia, [S.1.], v. 4, n. 1, p. 101-105, 1996.

SNEYERS, R. Sur l'analyse statistique des series d'obsevations. Gênova: Organização Mundial de Meteorologia, 1975. 192p. (OMN, Nota Técnica, 143).

STERN, N. Stern Review on the economics of climate change. 2006. Available at: $<$ http://www.hm-treasury.gov.uk>. Accessed on 8 dez. 2006.

SUGAHARA, S. Flutuações interanuais, sazonais e intrasazonais de precipitação no estado de São Paulo. 140f. 1991. Tese (Doutorado em Meteorologia) - Instituto de Astronomia, Geofísica e Ciências Atmosféricas, Universidade de São Paulo, São Paulo.

WORLD METEOROLOGICAL ORGANIZATION. Analysing long time series of hydrological data with respect to calimate variability. Geneva: WMO, 1988. (WMO/TD, 224).

YU, P.; YANG, T.; WU, C. 2002. Impact of climate change on water resources in southern Taiwan. Journal of Hydrology, Amsterdam, v. 260, p. 161-175, 2002. 